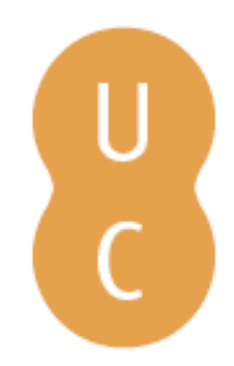

\title{
nommalina
}

\section{História Clínica}
Autor(es):
Oliveira, Guiomar

Publicado por: Imprensa da Universidade de Coimbra

URL persistente:

URI:http://hdl.handle.net/10316.2/43105

DOI:

DOI:https://doi.org/10.14195/978-989-26-1300-0_4

Accessed : $\quad$ 26-Apr-2023 08:20:08

A navegação consulta e descarregamento dos títulos inseridos nas Bibliotecas Digitais UC Digitalis, UC Pombalina e UC Impactum, pressupõem a aceitação plena e sem reservas dos Termos e Condições de Uso destas Bibliotecas Digitais, disponíveis em https://digitalis.uc.pt/pt-pt/termos.

Conforme exposto nos referidos Termos e Condições de Uso, o descarregamento de títulos de acesso restrito requer uma licença válida de autorização devendo o utilizador aceder ao(s) documento(s) a partir de um endereço de IP da instituição detentora da supramencionada licença.

Ao utilizador é apenas permitido o descarregamento para uso pessoal, pelo que o emprego do(s) título(s) descarregado(s) para outro fim, designadamente comercial, carece de autorização do respetivo autor ou editor da obra.

Na medida em que todas as obras da UC Digitalis se encontram protegidas pelo Código do Direito de Autor e Direitos Conexos e demais legislação aplicável, toda a cópia, parcial ou total, deste documento, nos casos em que é legalmente admitida, deverá conter ou fazer-se acompanhar por este aviso.

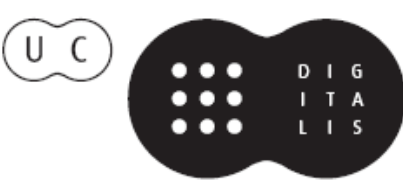


Capítulo 4.

História Clínica

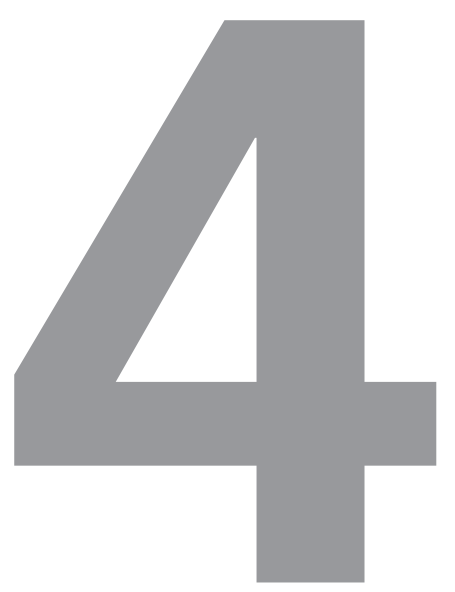

\section{Guiomar Oliveira}




\subsection{CONTEXTO}

Esta descrição da história clínica (HC) em Pediatria não é exaustiva, nem esgota o tema, são apenas linhas orientadoras. Por se tratar de uma aprendizagem pilar e estruturante de toda a clínica e arte pediátrica, no final, identifica-se a leitura que complementa esta lição.

A boa prática da medicina deve centrar-se no seu instrumento mais específico que é a história clínica. Nesta lição vamos adaptá-la à idade pediátrica.

Já sabemos que a Pediatria é a especialidade médica que engloba os cuidados integrais de saúde à criança e ao adolescente (dos 0 aos 18 anos) desde a sua conceção, numa perspetiva holística de promoção da saúde, prevenção e tratamento das doenças. Contempla ainda a defesa do seu bem-estar físico, mental e social. Esta visão global da Pediatria, centrada na promoção da melhor qualidade de vida para a criança e jovem, integrados no seu meio ambiente, não deve ser esquecida em nenhuma observação médica.

De salientar que cerca de $90 \%$ das consultas de saúde infantil e juvenil se processa ao nível dos cuidados de saúde primários (em 2009 no total de 3. 733. 226 consultas de idade pediátrica, 3. 256. 842 foram de saúde infantil e juvenil a cargo dos cuidados de saúde primários), só uma minoria se faz no Hospital. Na verdade, a maioria das crianças é saudável, e quando adoece, as situações clínicas são habitualmente benignas e autolimitadas. Não complicar é uma virtude, o que não significa banalizar. Toda a queixa tem que ser valorizada.
Apesar de ser útil seguir um guião na realização duma HC em Pediatria, à semelhança do adulto, aqui a sua flexibilização e redirecionamento tornam-se mais vezes necessários tendo em conta algumas especificidades, tais como: a idade (recém-nascido, lactente, pré-escolar, escolar e adolescente) e o contexto em que o médico observa a criança (rotina - a maioria; doença aguda, preocupações específicas e seguimento de vigilância; ou doença crónica).

A idade determina não só a anamnese; cada período etário tem caraterísticas, problemas e doenças específicas, mas também o modo de abordagem condicionado por um estadío de neurodesenvolvimento e físico exclusivo, em constante evolução.

A perspetiva holística e biopsicossocial da coIheita da história, da observação, da enumeração dos problemas e vantagens (fatores protetores) da criança e a respetiva intervenção, numa conceção salutogénica, devem ser seguidas.

Recordar que o que o médico diz, e como diz, pode influenciar de um modo positivo ou negativo a qualidade de vida das famílias.

As palavras são a mais poderosa droga utilizada pela humanidade ... Rudyard Kipling.

\section{Os cenários clínicos expectáveis na realização da HC serão então a estes níveis:}

1. Consulta de Vigilância de Saúde Infantil e Juvenil (CSIJ) (consultas de rotina).

2. Consulta por queixas/problema específico: situação aguda (cuidados de saúde primários de ambulatório ou hospitalares do 
grupo I, II ou III - serviço de urgência ou consulta de agudos e internamento); seguimento hospitalar em colaboração com os cuidados de saúde primários (doença crónica, preocupação...).

Em Portugal a CSIJ tem por base uma estrutura organizativa bem sedimentada, com uma experiência de quase 25 anos, através da implementação do Programa Nacional de Vigilância em Saúde Infantil e Juvenil (PNSIJ) (primeiro em 1992) pela Direção Geral da Saúde do Ministério da Saúde. As revisões subsequentes deram-se em 2002, 2005 e a última em 2013.

No atual PNSIJ (http://www.dgs.pt/?cr=24430) o número e a periodicidade de consultas de vigilância recomendadas são: primeiro ano de vida - sete (primeira semana de vida, 1, 2, 4, 6, 9 e 12 meses de idade); entre o 1 e os 3 anos - quatro consultas (15 e 18 meses, 2 e 3 anos); dos 4 aos 5 - duas consultas (4 e 5 anos); entre os 6 e os 9 anos - duas consultas [6 ou 7 anos (final $1^{\circ}$ ano do $1^{\circ}$ ciclo) e 8 anos]; dos 10 aos 18 anos - três consultas [10 anos (início $2^{\circ}$ ciclo),12/13 anos e 15/18 anos]. Detalhes dos objetivos, estrutura, temas de conversa e cuidados antecipatórios destas consultas, constam na última edição do Boletim de Saúde Infantil e Juvenil (BSIJ) que deve ser de leitura obrigatória (disponível nas maternidades ou centros de saúde).

Apesar desta calendarização prévia da cronologia das consultas, não deveremos perder o sentido do oportunismo e examinar a criança quando for conveniente.

O diálogo entre o médico e a família/criança, para realização da HC, deve ser encarado como um ato médico. Deve iniciar-se de um modo formal e amistoso, em espaço próprio e condigno. O médico, previamente, deve saber quem vai receber, e estar a par da informação disponível. Deve estar identificado e apresentar-se. é útil saber o nome da criança, idade, de onde vem, uma ou outra caraterística "positiva" que possa ser utilizada como frase inicial "quebra gelo". Deve falar calmamente e com linguagem adaptada à circunstância (cuidado com a utilização de termos médicos não compreensíveis, mas deve-se utilizar linguagem diferenciadora da população geral; é um médico...). Saber ouvir sem pressas (ou pelo menos não dar a perceber...). Registar (pode ser mentalmente) o importante da história e também as preocupações dos pais ou da criança, que deveremos reter, para esclarecimento posterior. Mostrar conhecimento e profissionalismo, dirigir o "diálogo" sem ser fundamentalista. Deve seguir-se uma ordem, mas poderemos usar o oportunismo "se vier à conversa". A experiência mostra que devemos ser cautelosos nas conclusões, o que parece à primeira informação, pode não ser; aguardar a emissão de "opinião" para o fim, depois da história completa. Até lá, vamos formulando hipóteses que vamos rejeitando ou apurando, mas só para nós. A família espera que no final se comprometa com um parecer clínico, mas fundamentado (pela história natural, pela fisiologia ou fisiopatologia). Se explicarmos de um modo compreensível a fundamentação para a nossa hipótese, a consulta torna-se psicoterapêutica. Este nível exige muito conhecimento e experiência.

\section{A mensagem a reter para os alunos é} que PRATIQUEM a HC, sempre que possível, quanto mais vezes, melhor. Não há histórias iguais. 
O interrogatório (anamnese) e a inspeção (sem tocar na criança) ocupam a maior parte do tempo dispensado à realização duma HC. A restante parte do exame físico é breve (cerca de um quarto do total). A observação deve ser completa e minuciosa, o que não significa invasiva (pode-se examinar a criança por "partes" sem a exigência de "despir e deitar" à semelhança do que se faz no adulto). A criança "pode não colaborar"; a arte do médico é observar sem ser necessária "negociação".

Faz sempre parte da HC a análise do BSIJ, bem como a avaliação do boletim de vacinas também conhecido por boletim individual de saúde. Ou seja, uma "consulta" sem recorrer a estes dois elementos pecará por ser incompleta. Recomenda-se um registo breve no BSIJ "do problema ou doença".

A descrição de $\mathrm{HC}$ que se segue para coIheita e redação é uma proposta; pode e deve ser adaptada e flexibilizada de acordo com a circunstância clínica.

\subsection{DESCRIÇÃO DO TEMA}

\section{Identificação}

Nome completo; sexo; raça;

data de nascimento;

data atual/de observação;

idade atual (meses ou anos);

nome dos pais; residência.

\section{Local e data da collheita;}

informante/acompanhante

(grau de confiança).

\section{Motivo de consulta}

(preferível - palavras do acompanhante ou adolescente)/motivo internamento, se for o caso (atenção: o motivo de internamento pode ser diferente do da consulta, já é uma decisão médica). Usar palavras chave (vómitos; tosse; dor abdominal ...se for internamento, tem que se especificar: vómitos incoercíveis, crise de asma com necessidade de oxigenoterapia...). O motivo pode também ser: consulta de vigilância dos ... dois meses.

\section{História da doença atual \\ (ou do/s problema/s/ queixa/s ou outras preocupações dos pais/ou rotina).}

Se a conversa for enquadrada em consulta de rotina é importante começar por perguntas em que se obtenham respostas "positivas", que dispõem bem a família: já anda, já fala, já conseguiu positiva a português... deixar para o fim as questões que abordam temas que frequentemente representam problemas difíceis de resolver: higiene do sono, tempo de contacto com ecrã, aprendizagem e comportamento escolar, de entre outros.

Se a consulta de rotina se transformar num espaço que é só para detetar problemas e emitir "correções" torna-se num momento desagradável. Realçar factos positivos, merecedores de elogio para a criança e para os pais, deve ser um objetivo a não descurar.

Quando o motivo da consulta é por "queixas" deve-se dar a devida atenção, ainda que pareçam banalidades. A criança/jovem, pais e eventualmente avós, estão preocupados. O estado 
emocional do médico deve ser adequado à situação, não pode perder o domínio.

O curso do interrogatório é uma arte. O equilíbrio entre o dirigismo necessário do médico, naquela circunstância clínica, e a permissividade da catarse "daquele doente" deve ser conseguido. Mais uma vez as perguntas "oportunas - fora de guião" podem ajudar nesta relação. Um cuidado que recomendo é que não se deve repetir perguntas que obriguem a respostas já múltiplas vezes dadas, e que podem ser facilmente obtidas em documentos escritos fiáveis (por exemplo no BSIJ, os factos relativos ao período pré-natal...). Podemos esclarecer dúvidas, mas já neste enquadramento...anteriormente referiu que, está registado que...pode-me esclarecer se...

Nesta fase ir observando o estado emocional da criança e da família... (tranquilos, preocupados, a confiar?), de modo a adequar os passos seguintes.

Os dados semiológicos "chave" devem ser escalpelizados: o quê, quanto, quando começaram (primeiro dia de doença - nem sempre fácil de obter, cabe ao médico essa decisão), $2^{\circ}, 3^{\circ} \ldots$ onde, como (súbito, progressivo) ...

A interação semiológica, evolução e sequência dos acontecimentos: primeiro a febre ou o exantema? Primeiro o vómito ou a dor? (ajudar a esclarecer, mas não se deve sugerir ou induzir a resposta...).

Questionar sobre a medicação prescrita (registar o fármaco por denominação comum internacional - DCl), a posologia (mg/Kg/dia), se conseguiu tomar (vomitou, cuspiu...) e outras medidas terapêuticas instituídas. Registar o efeito verificado.

Apesar da história se dirigir para uma situação clínica específica, não deveremos deixar de fazer brevemente uma revisão por sistemas orgânicos e perguntas genéricas sobre se está tudo bem com a alimentação, o sono, o crescimento, o neurodesenvolvimento e o comportamento de entre outros temas pediátricos.

\section{Antecedentes pessoais}

\subsection{Pré e perinatais}

Pré e perinatais: Gravidez (gesta $n^{\circ}$ ) - duração, incidentes e factores de risco, ecografias, diagnóstico pré-natal; parto (para $\left.n^{\circ}\right)$, local, tipo, intercorrências, qualidade da adaptação imediata à vida extrauterina (índice de Virgínea Apgar), cuidados na sala de parto, necessidade de reanimação, somatometria (classificação de acordo com idade gestacional - assinalar tabelas usadas); primeiros dias de vida - permaneceu junto da mãe? (ou necessidade de internamento em unidade de cuidados intensivos neonatais? Motivo e evolução - ver resumo de alta - normalmente anexo no BSIJ), quantos dias permaneceu na maternidade, se mamava bem. Incidentes neonatais: icterícia (história, níveis máximos de bilirrubina, necessidade de fototerapia ou exsanguíneotransfusão). Resultado de otoemissões acústicas. Registar as vacinas administradas na maternidade a idade do "rastreio neonatal" e o resultado.

Muito importante: integrar aqui os conhecimentos de obstetrícia e neonatologia. Consultar lição de neonatologia.

\subsection{História alimentar}

História alimentar: aleitamento - tipo; diversificação alimentar - quando e como, reações adversas. Alimentação atual (exemplo da véspera, se padrão normal). Especificar suplementos mineralo - vitamínicos e respetivas doses. 
Pesquisar especificamente erros alimentares comuns: por exemplo no lactente, prolongamento de alimentos passados, carga láctea e de cereais excessiva, de entre outros.

Muito importante: integrar aqui os conhecimentos de alimentação.

\subsection{Crescimento}

Crescimento: desde o nascimento - peso, altura/estatura e perímetro cefálico (referir os percentis e velocidade de crescimento). Índice de massa corporal; relação peso/idade estatural. Proporção entre o segmento superior e inferior (se de acordo com a idade). Interpretação do perfil do crescimento. Estatura alvo familiar se adequado.

Muito importante: integrar aqui os conhecimentos de crescimento.

\subsection{Desenvolvimento psicomotor \\ e comportamento}

Desenvolvimento psicomotor e comportamento (expressão clínica do neurodesenvolvimento): testar as aquisições das quatro áreas do neurodesenvolvimento em idades chave (postura e motricidade global; visão e motricidade fina; audição e linguagem; comportamento e adaptação social). Monitorizar e rastrear défices sensoriais (audição e visão). Pesquisar especificamente padrões de sono e de comportamento.

Muito importante: integrar aqui os conhecimentos de neurodesenvolvimento, sono e adolescência.

\subsection{Analisar o boletim de vacinas}

Registar as vacinas administradas e respetivas datas (idade cronológica), as reações adversas e as que estão em atraso.

Muito importante: integrar aqui os conhecimentos de vacinas.

\subsection{Doenças anteriores}

Doenças anteriores: agudas, crónicas, alérgicas, intoxicações/acidentes, internamentos motivo, medicação crónica, reações adversas a fármacos, cirurgias, seguimento hospitalar ou privado. Identificar o médico assistente. Verificar se tem sido cumprido o estabelecido no PNSIJ.

\section{(Consultar sempre o BSIJ).}

\section{Antecedentes familiares}

Especificar data de nascimento (idade) dos pais e irmãos, assim como a literacia e profissão dos pais, e se são consanguíneos.

De um modo breve registar as doenças e outros problemas de relevo como dificuldades de aprendizagem, problemas de comportamento, história de atopia e doenças heredofamiliares, entre outras. Devem abordar-se três gerações (irmãos, pais - tios, primos, avós e tios avós). Importante registar história de abortos espontâneos, nado mortos e mortes precoces. Pode ser útil em circunstâncias específicas desenhar a árvore genealógica.

Ambiente social em que vive: tipo de habitação, condições sanitárias e de espaço, animais domésticos.

Avaliar dinâmica familiar e rede de suporte sócio familiar (família nuclear, alargada, ou monoparental), rede de estabelecimentos de ensino e apoios sociais. 


\section{Exame objetivo}

O ambiente deve ser bem iluminado, agradável e climatizado. Pode ter brinquedos e livros, mas não muitos, senão é neles que se foca a atenção da criança. Um foco luminoso na mão do médico pode fazer milagres, e entreter uma criança enquanto se ausculta ou procede à palpação abdominal.

O médico deve adequar a atitude à idade funcional e emocional da criança. A observação deve ser delicada, o médico deve ter um ar amigável mas dirigente. As mãos acabadas de lavar, devem estar quentes, assim como o estetoscópio. Mostrar o que se vai fazer (i.e. "auscultar" a mão....). Conquistar a confiança e respeito da criança e acompanhante/s. Podese ir informando o que se está, ou vai fazer, e para quê.

Primeiro observa-se a criança onde estiver, fazendo-se uma inspeção cuidadosa. Depois fazemos uma abordagem por sistemas. Se estiver ao colo, é aí que a observamos. Os mais velhos podem deitar-se na marquesa, mas não é indispensável. Devemos observar todo o corpo, mas não é necessário que a criança esteja completamente despida. Podemos fazê-lo por áreas. Observar o tronco, depois o abdómen...este cuidado deve ser sobretudo aplicável às crianças entre os 12 meses e os dois a três anos, período em que têm um temperamento difícil, caracterizado por um comportamento de desafio e oposição. Antes e depois deste período podemos pedir para despir e deitar...

Só no final procedemos às manobras mais desagradáveis de observação da orofaringe, e otoscopia.

\section{Especificando:}

7.1 Observação preliminar: Estado da criança e da família (noção de gravidade do problema, família confiante, ansiosa, tranquila...).

\subsection{Inspeção: Estado geral, disposição, olhar, características da pele e mucosas, estado de hidratação e nutrição, padrão respiratório.}

7.3 Sinais vitais: Tempo de reperfusão capilar, frequência cardíaca, frequência respiratória, saturação periférica de oxigénio (se justificado), temperatura axilar, tensão arterial.

\subsection{Somatometria: Peso/altura/estatura/ perímetro cefálico (respetivos percentis), suas relações; índice de massa corporal.}

\subsection{Aquisições do neurodesenvolvimento. (ver lição de neurodesenvolvimento e comportamento).}

Nota: o exame neurológico está integrado na avaliação geral (relação da criança com o meio) e do neurodesenvolvimento. O exame neurológico clássico com pesquisa da função dos pares cranianos; da força muscular; do tónus; da marcha; das provas de coordenação motora; dos reflexos osteotendinosos, cutaneoabdominais, cutaneoplantar; da sensibilidade (táctil, térmica, postural, vibratória e dolorosa) e da fundoscopia deverá ser realizado se justificado pelas queixas ou achados prévios. 
7.6 Avaliação clínica da acuidade auditiva e visual (ver lição de neurodesenvolvimento e comportamento).

7.7 Pele, mucosas e fâneros (cabelos, pelos e unhas): morfologia, cor, hidratação, tumorações, angiomas, alterações da pigmentação.

\subsection{Cabeça/face: morfologia geral (ver} dismorfologia), fontanelas e suturas, olhos (distância interocular, pálpebras, estrabismo, epicanto, nistagmos, pupilas, córnea, conjuntiva e esclerótica), ouvidos (morfologia pavilhões auriculares, otoscopia), nariz (morfologia, permeabilidade aérea), boca (morfologia, mucosas, dentes, úvula, palato, orofaringe, amígdalas e pilares amigdalinos).

\subsection{Pescoço: morfologia geral (ver} dismorfologia), mobilidade, tumefações, adenopatias, tiroide.

A flexão da nuca é por sistema verificada, assim como a pesquisa dos restantes sinais meníngeos (de relevo em contextos febris).

\subsection{Tórax: morfologia geral (ver} dismorfologia), sinais de dificuldade respiratória, auscultação cardiopulmonar (ritmo cardíaco, sopros, murmúrio vesicular e ruídos adventícios) e percussão.

7.11 Abdómen: inspeção geral, palpação superficial e profunda (fígado, baço, massas, defesa, dor - caraterísticas), percussão e auscultação. Verificar sinais de irritação peritoneal.
7.12 Períneo, genitais e ânus: inspeção e palpação (ver lição patologia frequente em cirurgia de ambulatório), avaliar estadío pubertário (ver lição de adolescência).

\subsection{Membros, coluna e articulações:} morfologia geral (dismorfologia), simetria, mobilidade, sinais inflamatórios, pesquisar sinais de anomalias do desenvolvimento da anca. Pulsos femorais. (ver lição de Ortopedia variantes da normalidade e problemas frequentes).

\section{Resumo}

Deve ser conciso e conclusivo. Deve relevar os factos que pela sua positividade, ou negatividade, sejam importantes relativamente à queixa que traz a criança ao médico e aos dados que foram detetados através da anamnese e da observação global.

\section{Lista de problemas}

Escrevê-los por ordem de relevância no contexto "desta" história.

\section{Hipóteses de diagnóstico}

Destacar apenas as plausíveis "desta" história.

Discuti-las "telegraficamente" tendo em conta os diagnósticos diferenciais. Ou seja em cada uma das hipóteses de diagnóstico do problema ou "doença", listar os dados que estão a favor e os que estão contra.

Poderá ser necessário realizar exames complementares de diagnóstico (ECD) ou NÃO...

Ter em conta que a requisição de um ECD (decisão médica exclusiva) deve ser justificada. 
Ou seja, o seu resultado deve interferir na decisão médica subsequente, senão for o caso, pedir para quê?

\section{Exames complementares}

de diagnóstico

O pedido deve ser adequado à situação clínica (i.e. radiografia do tórax projeção póstero-anterior ou antero-posterior? Sumária de urina - método de colheita?) e a sua justificação expressamente assinalada.

Atenção: os ECD devem ser solicitados sequencialmente. Decidir qual deve ser o primeiro e de acordo com o seu resultado, eventualmente requisitar outro/s.

\section{Diagnóstico/s mais provável/eis}

ou somente os problemas

(integrando agora na $\mathrm{HC}$ os resultados do/s ECD

e a sua interpretação)

Listar por ordem de probabilidade e de importância o/s diagnóstico/s da/s doença/s ou problema/s.

\section{Diagnóstico definitivo}

(podemos não ter)

\section{Plano de intervenção}

Focar todos os diagnósticos e ou problemas previamente listados.

Informar sobre a evolução esperada (deve fazer parte do plano de intervenção médica).

Medicação: registos do fármaco por $\mathrm{DCl}$, da posologia (dose por kg e por dia, dose total por toma), da via de administração, do número de administrações por dia e da duração. Medicamentos prescritos em SOS devem seguir o mesmo rigor e registar uma informação clara de quando administrar.

Situações clínicas a vigiar: especificar.

Sinais ou sintomas de alarme que devem motivar nova observação médica, "neste" contexto: especificar.

\section{Informação sobre prognóstico}

História natural da doença ou problema (por exemplo: variante do normal).

\subsection{FACTOS A RETER}

A história clínica é o instrumento mais específico do médico e essencial em toda a abordagem clínica.

A história clínica é um ato médico. Deve ter o formalismo e a ética inerentes.

Não há duas histórias iguais...mesmo que seja outra vez "uma bronquiolite". Se quiser ter um bom desempenho dê conta que é diferente e única, e convença os outros.

Uma boa HC exige um vasto conhecimento teórico e prático. Pratique-a...parece fácil.

Apesar do guião, deve ser oportunista e flexível, mas sempre completo, e não perca o fio à meada...

O grupo etário, para além do motivo de consulta é o que mais determina a diferenciação da HC em Pediatria.

Não faça perguntas cuja resposta já foi dada várias vezes, retire a informação dos documentos escritos. Confirme só se tiver dúvidas.

Dirija as perguntas, mas não induza as respostas.

A uma criança não se pede. Às mais pequenas leva-se a que façam, as mais velhas informam-se. 
Nunca perca o domínio. Há situações difíceis.

Tudo que disser aos pais, fundamente-o de um modo compreensível. Reside aqui a parte psicoterapêutica da consulta e a confiança que a família depositará no médico.

Lembre-se que um médico é avaliado pelo conhecimento, pelo desempenho e pela atitude. A HC reflete isso tudo. Cuide-a.

\section{Leitura complementar}

Mota HC. Para uma história clínica (I). Acta Pediatr Port 2011;42(1):43-8.

Mota HC. Para uma história clínica II. Acta Pediatr Port 2011:42(2):84-9.

Carrilho EM. História clinica em pediatria. In: Palminha JM, Carrilho E. Orientação diagnóstica em pediatria: dos sinais e sintomas ao diagnóstico referencial. Lisboa: Lidel; 2002-2003.

Mota HC. Bases do raciocínio clinico. In: Palminha JM, Carrilho E. Orientação diagnóstica em pediatria: dos sinais e sintomas ao diagnóstico referencial. Lisboa: Lidel; 20022003. p 57-60.

History and examination. In:Lissauer T, Clayden G. Illustrated Textbook of Paediatrics. 4th ed. Elsevier Health Sciences. 2011. p 13-29. 